\title{
Characterization of the Al-3wt.\% Si Alloy in Unsteady-state Horizontal Directional Solidification
}

\author{
Diego Brito Carvalho ${ }^{\mathrm{a}}$,Emanuelle Casseb Guimarães ${ }^{\mathrm{a}}$, Antonio Luciano Moreira ${ }^{\mathrm{a}}$, \\ Daniel Joaquim Moutinho ${ }^{\mathrm{b}}$, José Marcelino Dias Filho ${ }^{\mathrm{b}}$, Otávio Lima da Rocha ${ }^{\mathrm{b} *}$ \\ ${ }^{a}$ Faculty of Mechanical Engineering, Federal University of Pará - UFPA, Rua Augusto Correa, 1, \\ CEP 66075-970, Belém, PA, Brazil \\ ${ }^{\mathrm{b}}$ Federal Institute of Education, Science and Technology of Pará - IFPA, Av. Almirante Barroso, 1155, \\ CEP 66093-020, Belém, PA, Brazil
}

Received: September 26, 2012; Revised: January 4, 2013

\begin{abstract}
The main purpose of this paper is to investigate both the columnar to equiaxed transition and primary dendritic arm spacings of Al-3wt.\%Si alloy during the horizontal directional solidification. The transient heat transfer coefficient at the metal-mold interface is calculated based on comparisons between the experimental thermal profiles in castings and the simulations provided by a finite difference heat flow program. Simulated curve of the interfacial heat transfer coefficient was used in another numerical solidification model to determine theoretical values of tip growth rates, cooling rates and thermal gradients that are associated with both columnar to equiaxed transition and primary dendritic arm spacings. A good agreement was observed between the experimental values of these thermal variables and those numerically simulated for the alloy examined. A comparative analysis is carried out between the experimental data of this work and theoretical models from the literature that have been proposed to predict the primary dendritic spacings. In this context, this study may contribute to the understanding of how to manage solidification operational parameters aiming at designing the microstructure of Al-Si alloys.
\end{abstract}

Keywords: columnar to equiaxed transition, primary dendritic spacing, directional solidification, unsteady-state conditions, Al-Si alloys

\section{Introduction}

The fundamental understanding of the relationship between solidification parameters and the resulting structure is essential for the development of methods for quality castings. As a consequence, it is critical for industrial applications to know the physical mechanisms that control the solidification process to improve the efficiency and performance of materials.

On the whole, the macrostructure of cast ingots consists of three different zones: the chill, columnar, and equiaxed zones. The origin of each one has been the subject of intense experimental and theoretical investigation because of the well-known correlation between grain structures and mechanical properties. The three zones may or may not be present in particular cases. The macrostructure of cast ingots has been of interest of researchers for many years, but, despite this interest, neither the macrostructure of an ingot can be predicted, nor there is any clear agreement on how the columnar to equiaxed transformation (CET) actually occurs. The CET has been reported to be dependent on thermal conditions associated with the casting process, including alloy system, alloy composition, melt superheat, mold temperature, mold material, heat-transfer coefficients at the metal-mold interface, cooling rate,

*e-mail: otvrocha@oi.com.br casting size, melt convection, transport of solute, and the concentration of nucleating particles, some of which vary with time and position during solidification ${ }^{1,2}$. Although many experiments ${ }^{3-5}$, analytical methods $\mathrm{s}^{6-8}$ and numerical simulations ${ }^{9-11}$ of this process have been carried out in recent years, the mechanism of CET is still not clear.

Dendritic growth is perhaps the most frequently observed phenomenon during the solidification whose morphology is characterized by primary $\left(\lambda_{1}\right)$, secondary $\left(\lambda_{2}\right)$ and tertiary $\left(\lambda_{3}\right)$ dendrite arm spacings. As the fluid flow in the interdendritic channels depends on these dendrite arm spacings, it is important to know the variation of these parameters during the solidification process to analyze microsegregation pattern which influences for instance the homogenization kinetics, ultimate tensile strength, ductility, toughness and yield tensile strenght of solidified alloys ${ }^{12-13}$. It is well known that dendrite fineness can be of even more importance than the grain size for the improvement of mechanical properties. Therefore, these structures can be considered as an important object of investigation with respect to the directional solidification of metallic alloys.

A number of directional solidification studies have been reported in the last decades to point out the effect of microstructure upon the mechanical properties, and different approaches and equations have been used with the purpose 
of modeling both theoretically and experimentally the primary and secondary dendrite arm spacings as a function of alloy solute concentration $\left(\mathrm{C}_{\mathrm{o}}\right)$, transient metal-mold heat transfer coefficient $\left(\mathrm{h}_{\mathrm{i}}\right)$, tip growth rate $\left(\mathrm{V}_{\mathrm{L}}\right)$, temperature gradient $\left(\mathrm{G}_{\mathrm{L}}\right)$ ahead of the macroscopic solidification front, tip cooling rate $\left(T_{R}\right)$ in the melt, type of mold and melt superheat ${ }^{14-25}$. Most studies have shown that for steady or unsteady growth conditions, the primary dendrite arm spacings decrease as the solidification rate or temperature gradient increases; however, there is no agreement in the literature regarding the effect of the alloy solute content on primary spacings. It has been reported in the majority of cases that these spacings increase as $\mathrm{C}_{\mathrm{o}}$ (for hypoeutetic alloys) increases for both steady and unsteady growth conditions.

Dendritic growth is controlled by the complex interplay of thermal, solutal, capillary, crystallographic anisotropy, thermodynamics and kinetics properties which occur on different length scales. This has led to an extensive theoretical and experimental study of the relationship between microstructure and solidification conditions. Because of the complexity of dendritic growth, analytical theories deal only with steady-state dendrite tip kinetics and only those theoretical models proposed by Hunt-Lu ${ }^{14}$ (primary dendritic arm) and Bouchard-Kirkaldy ${ }^{16,17}$ (primary and secondary dendritic arms) are supposed to encompass the dendritic growth in the unsteady-state regime. It has been observed, however, that these predictive theoretical models did not generate the experimental observations concerning the unsteady-state solidification of $\mathrm{Al}-\mathrm{Cu}$ and $\mathrm{Sn}-\mathrm{Pb}$ alloys ${ }^{20}$. The insertion of analytical expressions for $\mathrm{V}_{\mathbf{L}}$ and $\mathrm{T}_{\mathbf{R}}$ into experimental equations has been proposed in order to establish experimental formulae that relate cellular ${ }^{19,22}$ and dendritic ${ }^{20,23}$ spacings with the unsteady-state solidification variables. On the other hand, various numerical methods including cellular automata ${ }^{26-28}$, front-tracking methods ${ }^{29-31}$, phase field techniques ${ }^{32-34}$ and level set methods ${ }^{35-36}$ have been developed to study the growth of dendrites.

The gravity effects in relation to the CET and dendritic growth have been investigated with the chill placed in general on the bottom or top of the mold. In the case of vertical upward directional solidification, the influence of the convection is minimized when solute is rejected for the interdendritic regions, providing the formation of an interdendritic liquid denser than the global volume of liquid metal. When the process is carried out vertically downward, the system provides the melt convection which arises during the process. In the horizontal unidirectional solidification, when the chill is placed on the side of the mold, the convection in function of the composition gradients in the liquid always occurs. An interesting feature of the horizontal configuration is the gradient of solute concentration and density in vertical direction because solute-rich liquid falls down whereas free solvent-crystals rise due to buoyancy force. Moreover, there will also be a vertical temperature gradient in the sample as soon as a thermosolutal convection roll emerges. In spite of these particular physical characteristics, only a few studies have reported these important effects of melt convection and direction of growth on CET and dendrite arm spacings for this particular case.
It is well established that Al-Si alloys provide the most significant part of all shaped castings manufactured. This is mainly due to the outstanding effect of silicon in the improvement of casting characteristics, combined with other physical properties such as mechanical properties and corrosion resistance. Silicon is one of the most significant alloying elements incorporated in aluminium alloys. Its addition is to improve castability, fluidity, reduce shrinkage and to render superior mechanical properties ${ }^{37}$. In general, an optimum range of silicon content can be assigned to casting processes. For slow cooling rate processes (sand, plaster, investment), the range is $5-7 \mathrm{wt} . \%$, for permanent molds $7-9 \mathrm{wt} . \%$ and for die castings $8-12 \mathrm{wt} . \%^{38}$. These alloys are used in engineering components that are supposed to be exposed to critical wear conditions, such as engine parts, cylinder blocks and heads, pistons, water-cooled jackets, etc. Aluminum alloys with silicon contents as low as $2 \%$ have been used for casting, but silicon content usually is between 5 and $13 \%$. As an example of commercial compositions based on Al-3wt.Si alloy it can be mentioned the Al-4wt.Cu-3wt.Si ternary alloy that can be used in the manufacture of valve bodies and similar castings requiring pressure tightness and other applications where good casting characteristics, good weldability, pressure tightness, and moderate strength are required ${ }^{39}$.

The works proposed in the literature to analyze the CET and $\lambda_{1}$ profiles have shown that these variables are strongly influenced on the direction of solidification with respect to gravity. The microstructural development of hypoeutectic Al-Si alloys, as well as dendritic experimental growth laws have been reported in the literature, however, as reviewed, rares studies have reported influences of thermal parameters $\left(V_{L}, T_{R}\right.$ and $\left.G_{L}\right)$ on these structural variables during the horizontal unsteady-state directional solidification of alloys. In this context, this study may contribute to a better understanding of the thermal characteristics and processes occurred in the Al-Si alloys. The achieved results can be used for liquid metal processing in science and industry aiming at designing of a required alloy microstructure and mechanical properties of Al-Si alloys.

The main purpose of this paper is to investigate both the columnar to equiaxed transition and primary dendritic arm spacings of Al-3wt.\%Si hypoeutectic alloy during the horizontal directional solidification in unsteady-state heat flow conditions. A numerical solidification model is used to determine theoretical values of $V_{L}, T_{R}$ and $G_{L}$ that are associated with both columnar to equiaxed transformation and primary dendritic arm spacings. The experimental data concerning the columnar to equiaxed transition and primary spacings are related with these solidification thermal variables and experimental growth equations are derived. A comparative analysis is carried out between the experimental results of this work and theoretical models from the literature that have been proposed to predict the primary dendritic spacings concerning the horizontal directional solidification of Al-3wt.\%Si alloy.

\section{Experimental Procedure}

The experimental setup used to achieve directional solidification of Al-3 wt.\%Si alloy, shown in Figure 1, was designed at the Federal Institute of Education, Science 
and Technology of Pará, Brazil. It was designed in such a way that the heat was extracted only through a watercooled system placed in the lateral mold wall, promoting horizontal directional solidification. A stainless steel mold used was $110 \mathrm{~mm}$ long, $70 \mathrm{~mm}$ wide, $60 \mathrm{~mm}$ high and $3 \mathrm{~mm}$ thick. The lateral inner mold walls were covered with a layer of insulating alumina and the upper part of the mold was closed with refractory material to minimize heat losses from the mold to a minimum. The thermal contact condition at the metal-mold interface was also standardized with the heatextracting surface being polished. Continuous temperature measurements were made during solidification at different positions in the casting and the data were acquired automatically. For the measurements, a set of five fine type $\mathrm{K}$ thermocouples accurately located with respect to the metal-mold interface was used, as shown by the schematic representation presented in Figure 1. The thermocouples were calibrated at the melting point of aluminum, exhibiting fluctuations of about $1.0{ }^{\circ} \mathrm{C}$, were connected by a data acquisition system and were stored on a computer. The thermocouples were sheathed in $1.6 \mathrm{~mm}$ diameter steel tubes, and positioned at 5, 10, 15, 30 and $50 \mathrm{~mm}$ from the heat-extracting surface. Previous measurements of the temperature field were carried out confirming that the described experimental apparatus fulfills the requirement of a unidirectional heat flow in horizontal direction.

Experiments were carried out with Al-3wt.\%Si hypoeutectic alloy. The chemical compositions of metals that were used to prepare the alloy investigated are those reported in Table 1. The thermophysical properties of this alloy are summarized in Table 2 . The alloy was melted in situ and starting melt superheat, chosen in order to favor the columnar to equiaxed transition, was standardized in $10 \%$ above the liquidus temperature using an electrical furnace whose heaters had their power controlled in order to permit the desired superheat to be achieved. Approaching the superheat temperature, the mold was taken from the heater and set immediately on a water-cooled stainless steel chill. Water circulated through this cooling jacket keeping the stainless steel plate during the solidification at a constant temperature of about $25^{\circ} \mathrm{C}$ and thus inducing a longitudinal heat transfer from the mold. Solidification occurred dendritically from the lateral chill surface, forming a columnar structure. The ingots were sectioned along

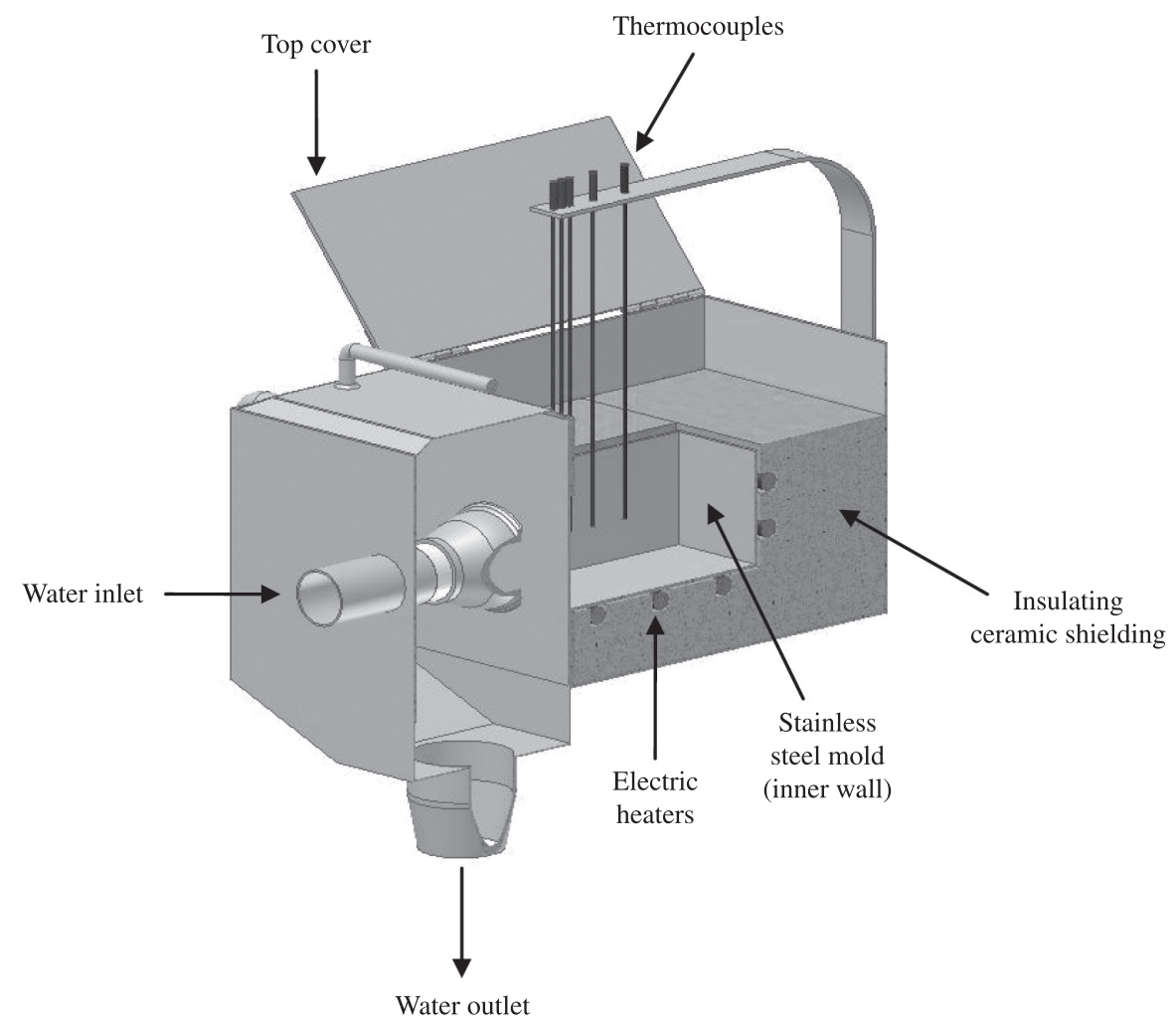

Figure 1. Furnace schematic showing thermocouples located at different positions from the metal-cooling chamber interface.

Table 1. Chemical compositions (wt. pct) of metals used to prepare the Al-3wt.\%Si alloy.

\begin{tabular}{cccccccccccc}
\hline Metal & $\mathbf{A l}$ & $\mathbf{F e}$ & $\mathbf{N i}$ & $\mathbf{S i}$ & $\mathbf{P}$ & $\mathbf{C a}$ & $\mathbf{T i}$ & $\mathbf{Z n}$ & $\mathbf{G a}$ & $\mathbf{V}$ & $\mathbf{C u}$ \\
\hline $\mathrm{Al}$ & 99.707 & 0.176 & 0.006 & 0.062 & - & - & 0.009 & 0.007 & 0.012 & 0.011 & 0.005 \\
$\mathrm{Si}$ & 0.109 & 0.316 & 0.010 & 99.596 & 0.010 & 0.021 & 0.046 & - & - & - & - \\
\hline
\end{tabular}


Table 2. Casting material used for experimentation and the corresponding thermophysical properties ${ }^{4}$.

\begin{tabular}{|c|c|c|c|c|c|c|c|c|c|c|}
\hline Properties & $\begin{array}{c}\text { Thermal } \\
\text { conductivity }\end{array}$ & $\begin{array}{c}\text { Specific } \\
\text { heat }\end{array}$ & Density & $\begin{array}{l}\text { Latent } \\
\text { heat of } \\
\text { fusion }\end{array}$ & $\begin{array}{c}\text { Solute } \\
\text { diffusivity }\end{array}$ & $\begin{array}{c}\text { Gibbs- } \\
\text { Thomson } \\
\text { coefficient }\end{array}$ & $\begin{array}{c}\text { Solidus } \\
\text { temperature }\end{array}$ & $\begin{array}{c}\text { Liquidus } \\
\text { temperature }\end{array}$ & $\begin{array}{l}\text { Partition } \\
\text { coefficient }\end{array}$ & $\begin{array}{l}\text { Liquidus } \\
\text { slope }\end{array}$ \\
\hline \multirow{2}{*}{$\begin{array}{l}\text { Symbol/ } \\
\text { units }\end{array}$} & $\begin{array}{c}\mathrm{K}_{\mathrm{S}}[\mathrm{W} / \mathrm{m} . \mathrm{K}] \\
(\text { solid })\end{array}$ & $\begin{array}{c}\mathrm{c}_{\mathrm{s}}[\mathrm{J} / \mathrm{kg} . \mathrm{K}] \\
\text { (solid) }\end{array}$ & $\begin{array}{c}\rho_{\mathrm{s}}\left[\mathrm{kg} / \mathrm{m}^{3}\right] \\
\text { (solid) }\end{array}$ & \multirow{2}{*}{ - L [J/kg] } & \multirow{2}{*}{$\mathrm{D}\left[\mathrm{m}^{2} / \mathrm{s}\right]$} & \multirow{2}{*}{$\Gamma[\mathrm{m} . \mathrm{K}]$} & \multirow{2}{*}{$\mathrm{T}_{\mathrm{s}}\left[{ }^{\circ} \mathrm{C}\right]$} & \multirow{2}{*}{$\mathrm{T}_{\mathrm{L}}\left[{ }^{\circ} \mathrm{C}\right]$} & \multirow{2}{*}{$\mathrm{k}_{\mathrm{o}}$} & \multirow{2}{*}{$\begin{array}{c}\mathrm{m}_{\mathrm{L}} \\
(\mathrm{K} / \mathrm{wt} \mathrm{pct})\end{array}$} \\
\hline & $\begin{array}{c}\mathrm{K}_{\mathrm{L}}[\mathrm{W} / \mathrm{m} \cdot \mathrm{K}] \\
\text { (liquid) }\end{array}$ & $\begin{array}{l}\mathrm{c}_{\mathrm{L}}[\mathrm{J} / \mathrm{kg} \cdot \mathrm{K}] \\
\text { (liquid) }\end{array}$ & $\begin{array}{c}\rho_{\mathrm{L}}\left[\mathrm{kg} / \mathrm{m}^{3}\right] \\
\text { (liquid) }\end{array}$ & & & & & & & \\
\hline \multirow{2}{*}{ Al-3wt. $\% \mathrm{Si}$} & 121 & 963 & 2695 & \multirow{2}{*}{-389187} & \multirow{2}{*}{$3 \times 10^{-9}$} & \multirow{2}{*}{$9 \times 10^{-8}$} & \multirow{2}{*}{577} & \multirow{2}{*}{644} & \multirow{2}{*}{0.13} & \multirow{2}{*}{6} \\
\hline & 91 & 1084 & 2385 & & & & & & & \\
\hline
\end{tabular}

its longitudinal direction, which is parallel to both the sample axis and the direction of solidification. After this, the metallographic specimens were mechanically polished with abrasive papers and subsequently etched with an acid solution composed of $5 \mathrm{~mL} \mathrm{H}_{2} \mathrm{O}, 60 \mathrm{~mL} \mathrm{HCl}, 30 \mathrm{~mL}$ $\mathrm{HNO}_{3}$ and $5 \mathrm{~mL} \mathrm{HF}$ to reveal the macrostructures. Etching was performed at a temperature between $30^{\circ} \mathrm{C}$ and $35^{\circ} \mathrm{C}$ during approximately 10 minutes. The position of the CET was clearly delineated by visual observation and optical microscopy on the etched surface and its distance from the side of the sample was measured.

Selected transverse (perpendicular to the growth direction) sections of the directionally solidified specimens at 5, 10, 15, 20, 30, 40, 50 and $60 \mathrm{~mm}$ from the metal-mold interface were electropolished and etched with a solution of $5 \% \mathrm{HF}$ in water for micrograph examination. Image processing system Olympus BX51 and Image Tool (IT) software were used to measure primary arm spacings (about 20 independent readings for each selected position, with the average taken to be the local spacing) and their distribution range. The method used for measuring the primary arm spacing on the transverse section was the triangle method ${ }^{18,20}$.

In this study, the results of experimental thermal analysis were compared with theoretical values given by a finite difference heat flow model ${ }^{40,41}$ to determine $h_{i}$ profile. This method is supported by temperature measurements at known locations inside the heat conducting body and makes a complete mathematical description of the physics of the process which, at each time step, includes the following: a suitable initial value of $h_{i}$ is assumed and, with this value, the temperature of each reference location in casting at the end of each time interval $\Delta \mathrm{t}$ is simulated by the numerical model. The correction in $h_{i}$ at each interaction step is made by a value $\Delta \mathrm{h}_{\mathrm{i}}$ and new temperatures are estimated $\left[T_{e s t}\left(h_{i}+\Delta h_{i}\right)\right]$ or $\left[T_{e s t}\left(h_{i}-\Delta h_{i}\right)\right]$. With these values, sensitivity coefficients $(\phi)$ are calculated for each interaction, given by:

$$
\phi=\frac{T_{e s t}\left(h_{i}+\Delta h_{i}\right)-T_{e s t}\left(h_{i}\right)}{\Delta h_{i}}
$$

The procedure determines the value of $h_{i}$, which minimizes an objective function defined by:

$$
F\left(h_{i}\right)=\sum_{i=1}^{n}\left(T_{e s t}-T_{\exp }\right)^{2}
$$

where $\mathrm{T}_{\text {est }}$ and $\mathrm{T}_{\text {exp }}$ are the estimated and the experimentally measured temperatures at various thermocouples locations and times, and $\mathrm{n}$ is the iteration stage. An automatic search has selected the best theoretical-experimental fit from a range of transient heat transfer coefficients profiles. The interfacial heat transfer coefficient has been expressed as a power function of time, given by the general form $h_{i}=C(t)^{-n}$ where $h_{i}(\mathrm{~W} / \mathrm{mK}), \mathrm{t}(\mathrm{s})$ and $\mathrm{C}$ and $\mathrm{n}$ are constants which depend on mold material, superheat and alloy composition.

Simulated $h_{i}$ curve was used in another numerical solidification model ${ }^{40}$ in order to determine theoretical values of $\mathrm{V}_{\mathbf{L}}$ and $\mathrm{T}_{\mathbf{R}}$, which are usually associated with both CET and primary dendrite arm spacings. The values of thermal parameters $V_{\mathbf{L}}$ and $T_{\mathbf{R}}$ are explicitly calculated at each time increment $(0.001 \mathrm{~s})$ of the simulation. Although the numerical model ${ }^{40,41}$ employed for $h_{i}$ theoretical estimation does not take effects on convection in liquid into account, it was selected from the literature as the most appropriate model for representing the solidification conditions considered in this study. Moreover, it has been frequently used by other authors in researching unidirectional solidification in horizontal ${ }^{41}$, downward vertical ${ }^{40,42,43}$ and rotary systems ${ }^{44}$, which produce melt convection effects.

\section{Results and Discussion}

\subsection{Transient heat transfer coefficient at metal- mold interface $\left(h_{\mathrm{i}}\right)$}

Experimental cooling curves for the five thermocouples inserted into the casting during solidification of the alloy investigated in this study are shown in Figure 2. For determination of the values of $h_{i}$, the referring thermal profile to the thermocouple next to the cooled base $(5 \mathrm{~mm})$ was used, position in which eventual heat losses by lateral walls of the mold is more improbable. Experimental thermal responses were compared to those simulated numerically by using transient $h_{i}$ profile which provides best curve fitting, as shown in Figure 3. The time dependence of overall $h_{i}$ during the course of experiment of horizontal directional solidification of hypoeutectic Al-3wt.\%Si alloy in a polished cooled mold is shown in Figure 4. It is noticed a significant reduction of $h_{i}$ values in the initial instants of the process, mainly in the first 25 seconds of the total time of solidification. From this time until the 100 seconds, a gradual reduction of these values occurs. After this time, the $h_{i}$ profile remains practically constant until the end of the solidification. During horizontal directional solidification the heat transfer coefficient is high in the initial stages of 
solidification as a result of the good surface conformity between the liquid core and the solidified shell. The mold expands while solidification progresses due to the absorption of heat, and the solid metal shrinks during cooling. As

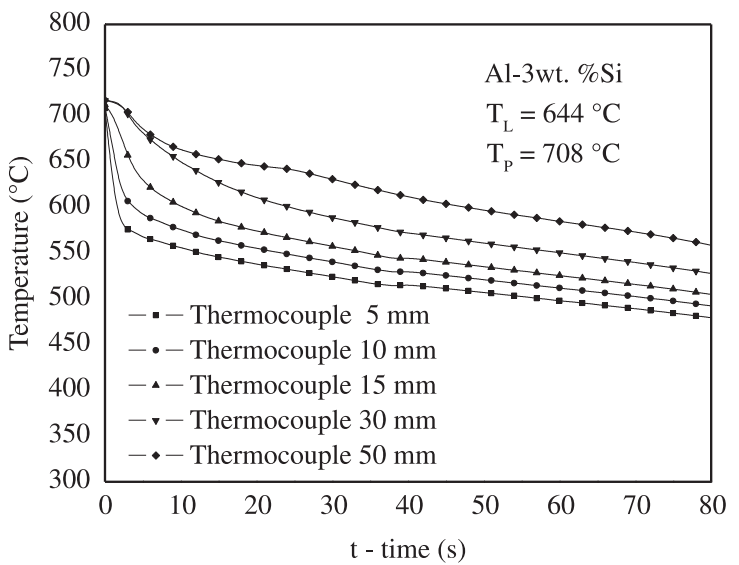

Figure 2. Experimental thermal responses of temperature vs. time for five thermocouples located at different positions from the metal-cooling chamber interface. $\mathrm{T}_{P}$ is the initial melt temperature.

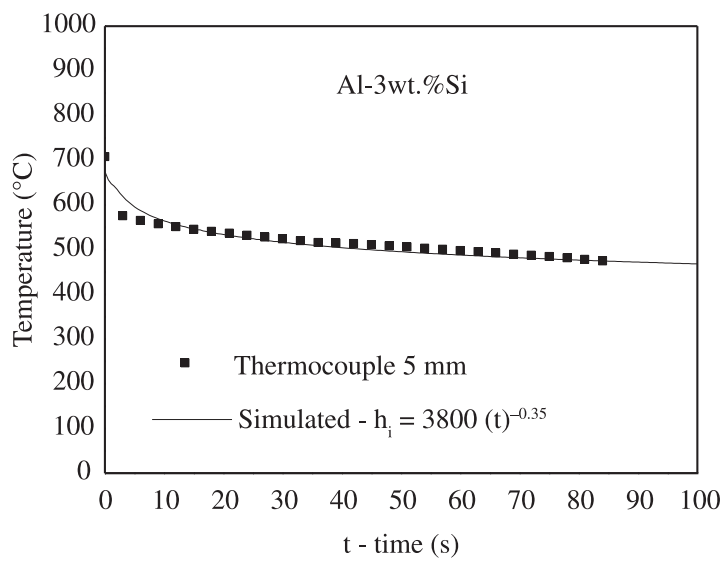

Figure 3. Simulated and measured temperature responses of thermocouple at position $5 \mathrm{~mm}$ from the heat-extracting surface of Al-3wt.\%Si alloy investigated.

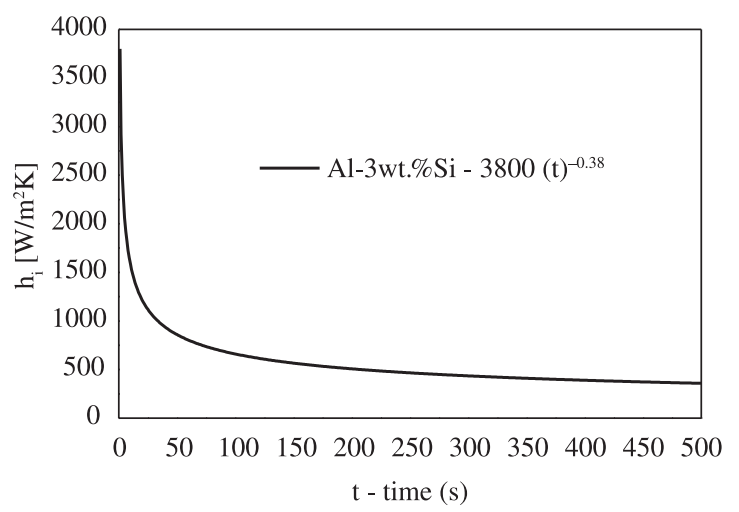

Figure 4. Evolution of the metal-mold interfacial heat transfer coefficient as a function of time. a consequence, a gap develops at this interface because pressure becomes insufficient to guarantee a conforming contact between the surfaces. Once the air gap is created, the heat transfer across the metal-mold interface decreases rapidly and a relatively constant value of $h_{i}$ is attained.

\subsection{Columnar to equiaxed transition (CET)}

The directionally solidified structure of Al-3wt.\% Si alloy analyzed is shown in Figure 5. The macrostructure consists of elongated columnar grains aligned approximately parallel to the heat flow direction, as well as of equiaxed grains of varying extent and random orientations. The CET is formed at the shared boundary at which the two zones meet. Entrapped equiaxed grains are not observed in the columnar region close to the transition. The basic feature of the transition shown by the macrostructure is that the CET is sharp, i.e., there is clear evidence that the structural transformation has occurred along a plane parallel to the chill wall because of the high density of rapidly growing equiaxed grains. The CET has occurred at $68 \mathrm{~mm}$ measured from the metal/cooling chamber interface.

\subsection{Solidification thermal parameters $\left(V_{\mathbf{L}}, T_{\mathbf{R}^{\prime}}\right.$ and $G_{\mathbf{L}}$ )}

It is well known that the primary dendritic arm spacings are dependent on solidification thermal variables such as $V_{L}$, $T_{R}$, and $G_{L}$ all of which vary with time and position during solidification. In order to determine more accurate values of these parameters, the results of experimental thermal analysis have been used to determine the displacement of the liquidus isotherm, i.e., the thermocouples readings have also been used to generate a plot of position from the metal/ mold interface as a function of time corresponding to the liquidus front passing by each thermocouple. A curve fitting technique on such experimental points has generated power functions of position as a function of time. Experimental positions of liquidus isotherms as a function of time are shown in Figure 6 compared with the theoretical results furnished by the numerical solidification model ${ }^{42}$, which used the corresponding value of the transient heat-transfer coefficient presented in Figure 4. A good agreement has been observed between the experimental results and numerical values for the alloy Al-3wt.\%Si investigated.

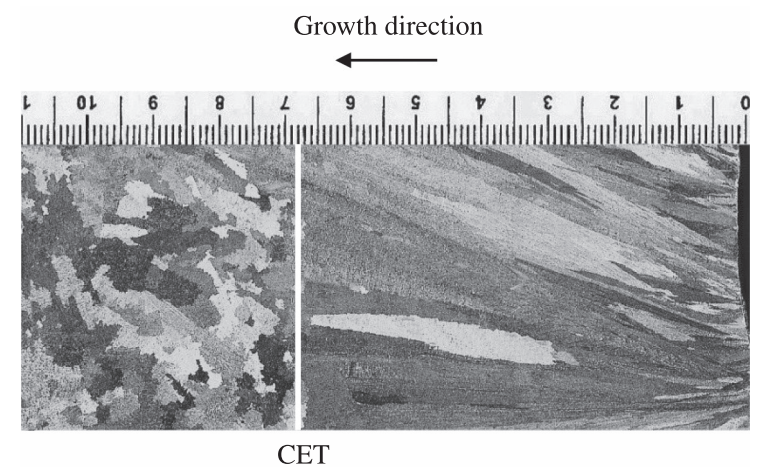

Figure 5. Solidification macrostructure and the corresponding CET position (cm). 
The derivative of this function with respect to time has yielded values for $\mathrm{V}_{\mathbf{L}}$. Figure 7 shows a comparison between experimental and numerical predictions of $\mathrm{V}_{\mathbf{L}}$. The data acquisition system, in which temperature readings are collected at a frequency of $0.5 \mathrm{~s}$, permits accurate determination of the slope of the experimental cooling curve. The $T_{R}$ profile was calculated by considering the thermal data recorded immediately after the passing of the liquidus front by each thermocouple whose values are compared with theoretical predictions furnished by the numerical model ${ }^{42}$ in Figure 8. Finally, experimental and theoretical results of $G_{L}$ as a function of position from the chill provided by the numerical model ${ }^{42}$ are shown in Figure 9 in which it is

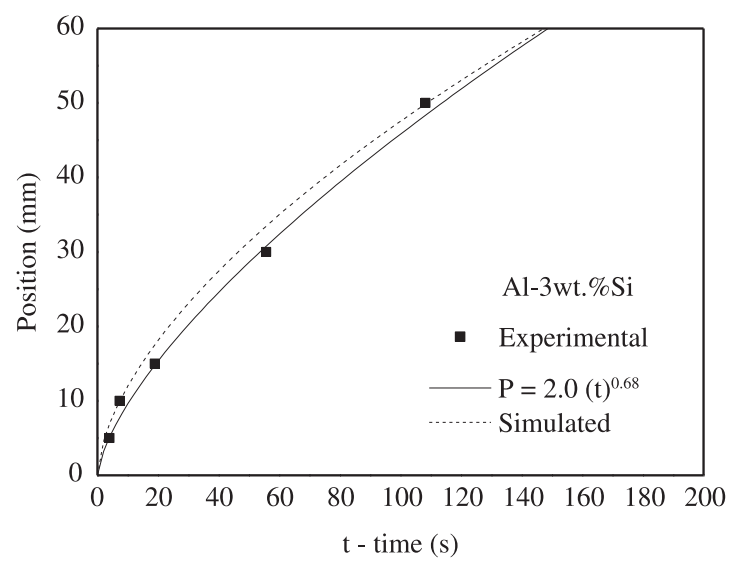

Figure 6. Experimental position of liquidus isotherm from the metal-mold interface as function of time.

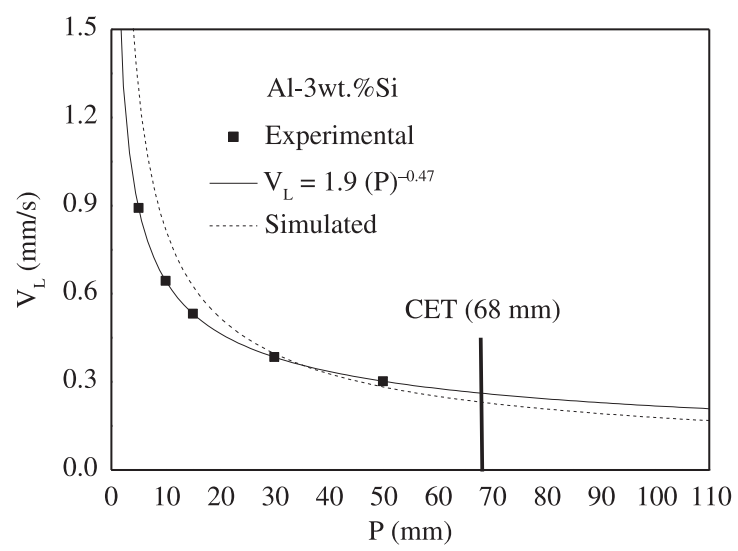

Figure 7. Tip growth rate as a function of position from the metal-mold interface for the Al- $3 \mathrm{wt}$.\% Si alloy during horizontal solidification. shown that $G_{L}$ decreases with distance from the metal-mold interface, as expected. A good agreement can be observed between the experimental values of $\mathrm{V}_{\mathbf{L}}, \mathrm{T}_{\mathbf{R}}$ and $\mathrm{G}_{\mathbf{L}}$ and those numerically simulated for the alloy examined. Experimental and numerical results of $\mathrm{V}_{\mathbf{L}}, \mathrm{T}_{\mathbf{R}}$ and $\mathrm{G}_{\mathbf{L}}$ at CET position are listed in Table 3. As we can notice, the experimental and numerical values found for these thermal parameters are relatively close to each other.

\subsection{Primary dendritic arm spacings $\left(\lambda_{1}\right)$}

Figure 10 presents microstructures of cross section of samples at 10,30, and $60 \mathrm{~mm}$ from metal/mold interface, showing the primary dendrite arms. The dendrite arm

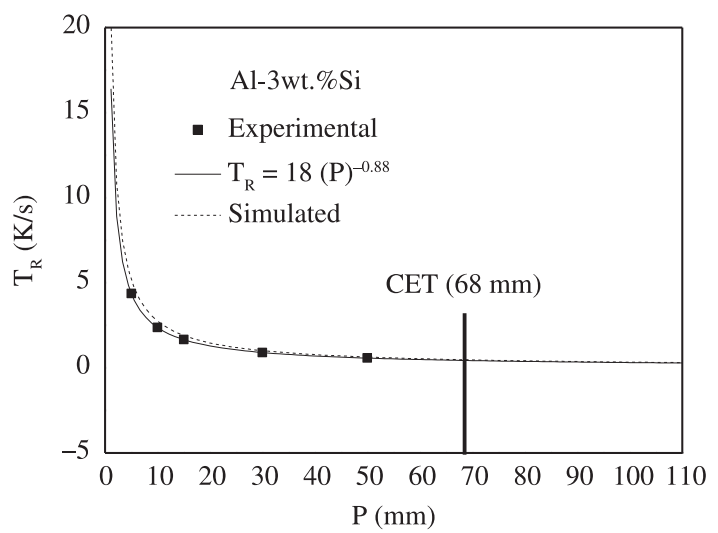

Figure 8. Tip cooling rate as a function of position from the metal-mold interface for the Al- $3 \mathrm{wt} . \%$ Si alloy during horizontal solidification.

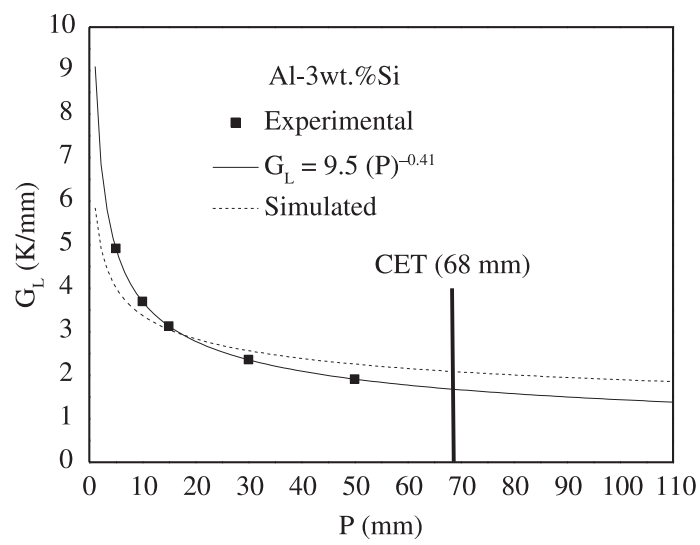

Figure 9. Temperature gradient as a function of position from the metal-mold interface for the Al-3wt.\%Si alloy during horizontal solidification.

Table 3. Experimental and numerical results for the solidification thermal parameters associated to the CET position.

\begin{tabular}{|c|c|c|c|c|c|c|c|}
\hline \multirow{3}{*}{ Alloy } & \multirow{3}{*}{$\begin{array}{c}\text { CET } \\
\text { position } \\
(\mathbf{m m})\end{array}$} & \multicolumn{6}{|c|}{ Thermal parameters } \\
\hline & & \multicolumn{2}{|c|}{$\mathrm{V}_{\mathrm{L}}(\mathrm{mm} / \mathbf{s})$} & \multicolumn{2}{|c|}{$T_{R}(K / s)$} & \multicolumn{2}{|c|}{$G_{L}(K / \mathbf{m m})$} \\
\hline & & Experimental & Numerical & Experimental & Numerical & Experimental & Numerical \\
\hline Al-3wt. $\% \mathrm{Si}$ & 68 & 0.26 & 0.23 & 0.44 & 0.48 & 1.68 & 2.09 \\
\hline
\end{tabular}




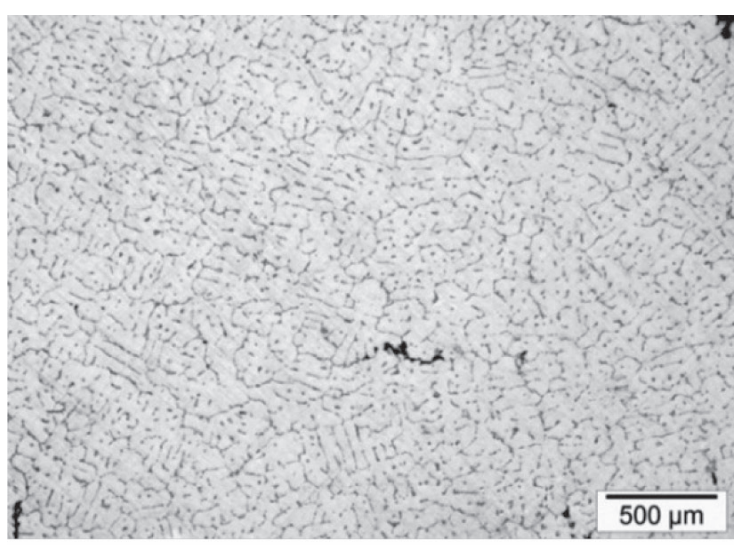

(a)

$\lambda_{1}=181 \mu \mathrm{m} ; \mathrm{V}_{\mathrm{L}}=0,64 \mathrm{~mm} / \mathrm{s} ; \mathrm{T}_{\mathrm{R}}=2,37^{\circ} \mathrm{C} / \mathrm{s}$.

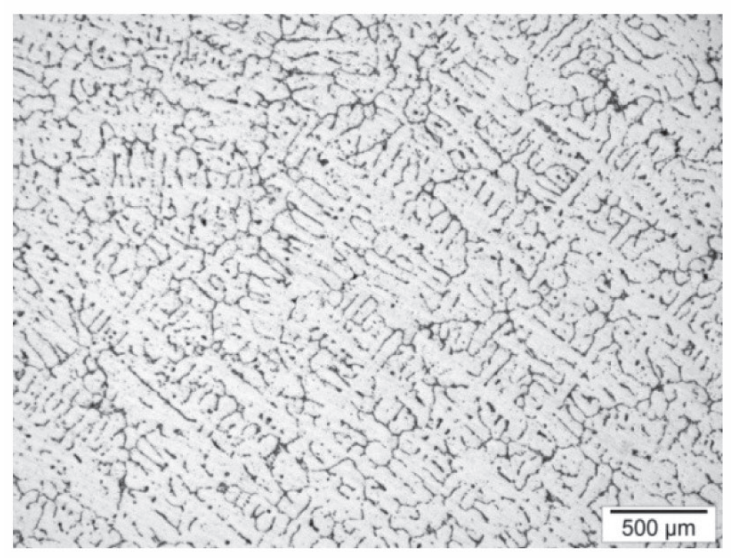

(b)

$\lambda_{1}=269 \mu \mathrm{m} ; \mathrm{V}_{\mathrm{L}}=0,38 \mathrm{~mm} / \mathrm{s} ; \mathrm{T}_{\mathrm{R}}=0,90{ }^{\circ} \mathrm{C} / \mathrm{s}$

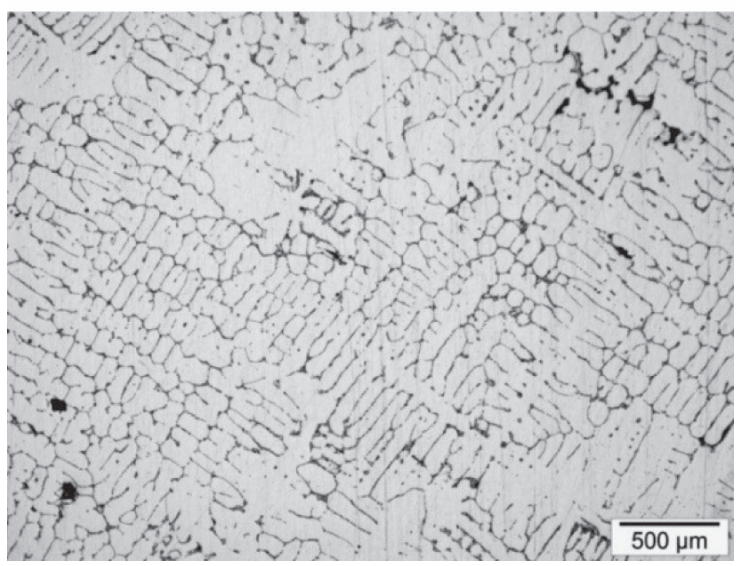

(c)

$\lambda_{1}=345 \mu \mathrm{m} ; \mathrm{V}_{\mathrm{L}}=0,28 \mathrm{~mm} / \mathrm{s} ; \mathrm{T}_{\mathrm{R}}=0,49^{\circ} \mathrm{C} / \mathrm{s}$

Figure 10. Micrographs of unidirectionally solidified Al-3wt.\%Si alloy cross section showing the variation in primary interdendric spacings with the distance from the cooled stainless steel chill. (a) Distance from chill $10 \mathrm{~mm}$, (b) Distance from chill $30 \mathrm{~mm}$, and (c) Distance from chill $60 \mathrm{~mm}$. spacings were sufficiently distinct to make reasonably accurate measurements along the casting length. Figure 11 shows the average experimental values of primary dendritic spacings as a function of distance from the metal-mold interface obtained in this work. It is observed that these dendrite arm spacings increase with the distance from the heat-extracting surface of Al-Si alloy investigated. In order to correlate the primary dendrite arm spacings measured from the afore-mentioned microstructures with solidification thermal variables, they are plotted as a function of $V_{\mathbf{L}}$ and $T_{\mathbf{R}}$ in Figures 12 and 13. The average dendritic spacings along with the standard variation are presented in these figures, with the lines representing an experimental power function fit with the experimental points. It is observed that the use of a water-cooled mold imposes higher values of tip growth rates and cooling rates near the casting surface and a decreasing profile along the casting due to the increasing thermal resistance of the solidified shell with distance from the cooled surface. This influence translates to the observed experimental values of primary dendritic spacings. As shown in Figure 12, the primary dendrite arm spacing was found to decrease as the $V_{L}$ is increased. Most of the results from the literature

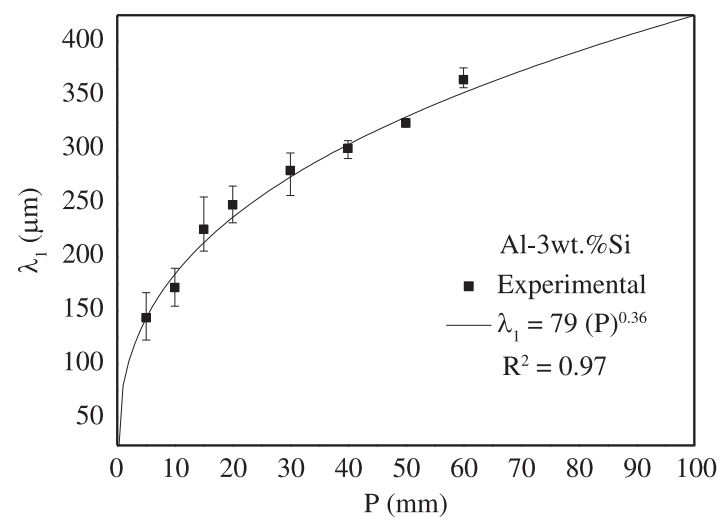

Figure 11. Primary dendrite arm spacing as a function of distance from chill for the Al- 3wt.\%Si alloy.

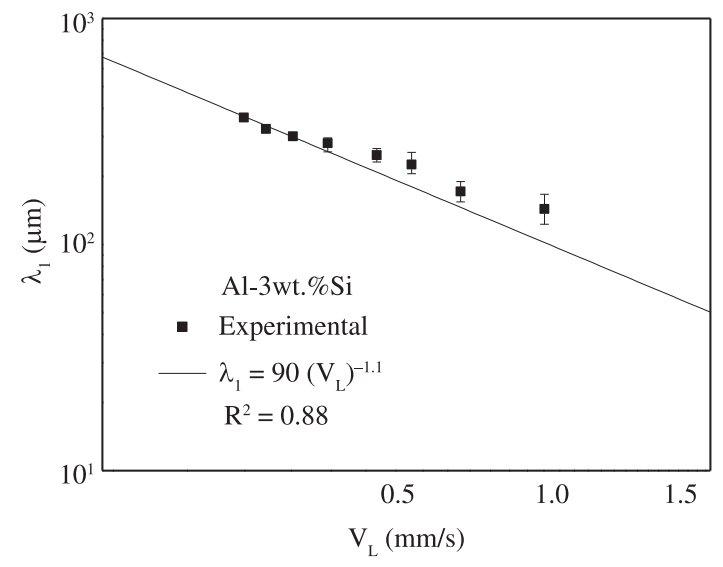

Figure 12. Primary dendrite arm spacing as a function of tip growth rate for the Al- $3 \mathrm{wt} . \% \mathrm{Si}$ alloy. 


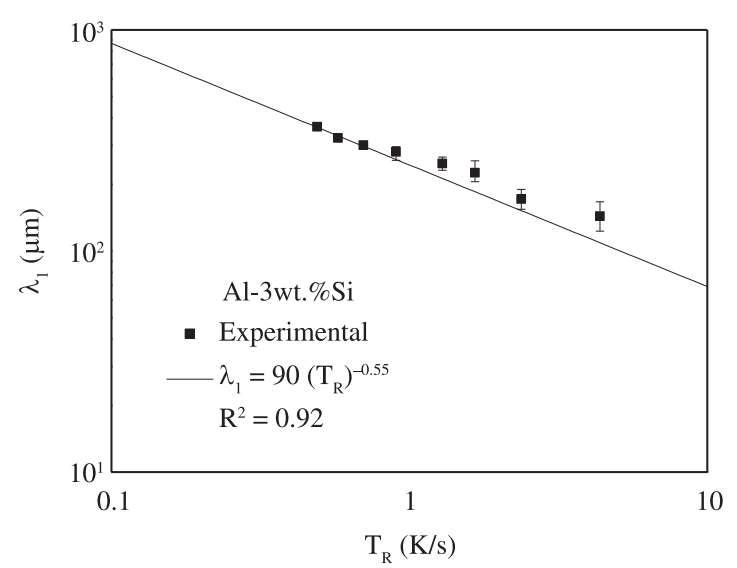

Figure 13. Primary dendrite arm spacing as a function of cooling rate for the $\mathrm{Al}-3 \mathrm{wt} . \% \mathrm{Si}$ alloy.

pertaining to $\lambda_{1}$ in hypoeutectic alloys also indicate a decrease in spacing with decreasing $\mathrm{V}_{\mathbf{L}}$. Furthermore, a power law function characterizes the experimental variation of primary spacings with tip growth rate with an index of -1.1 , i.e. $\lambda_{\mathbf{1}} \alpha \mathrm{V}_{\mathbf{L}}^{-1.1}$. It can be observed in Figure 13 that a -0.55 power law characterizes the experimental variation of primary spacings with cooling rate. This is in agreement with observations reported by Peres et al. ${ }^{4}$ and Rocha et al..$^{20}$ that exponential relationships $\lambda_{1}=\operatorname{constant}\left(\mathrm{T}_{\mathrm{R}}\right)^{-0.55}$ best generate the experimental variation of primary dendritic arms with cooling rate along the unsteady-state solidification of $\mathrm{Al}-\mathrm{Si}$ alloys as well as $\mathrm{Sn}-\mathrm{Pb}$ and $\mathrm{Al}-\mathrm{Cu}$ alloys, respectively.

Figure 14 shows the comparisons between the present experimental results of primary spacings with theoretical predictions furnished by unsteady-state predictive models: Hunt-Lu's model ${ }^{14}$ and Bouchard-Kirkaldy's mode ${ }^{16,17}$, with a calibration factor $\mathrm{a}_{1}=250$ for Al-Si alloys, as suggested by these authors ${ }^{17}$. It can be seen that both models underestimate the primary spacings. The experimental values, however, are close to the upper limit of Hunt-Lu's model. The predicted dendritic spacings calculated for unsteady solidification by Hunt-Lu's and BouchardKirkaldy's models are subjected to deviations caused mainly by the unaccounted diffusion relaxations and coring reductions for primary spacings ${ }^{17}$. Other uncertainties such as thermophysical properties can also affect the calculated results. Furthermore, the assumptions that the partition coefficients and the liquidus slope are constant throughout the entire solidification range is quite inaccurate for some binary systems. All these uncertainties, therefore, must be considered when comparing experimental results to those calculated ${ }^{20}$. Finally, it should be emphasized that the Hunt-Lu's and Bouchard-Kirkaldy's models have been proposed with a view to characterize dendrite arm spacings during solidification processes in which the latent heat is extracted unidirectionally from metal-mold system. In the horizontal directional solidification, however, there will also be a vertical temperature gradient in the metal liquid. Therefore, the phenomenon of solidification in this case can be considered as two-dimensional which promotes

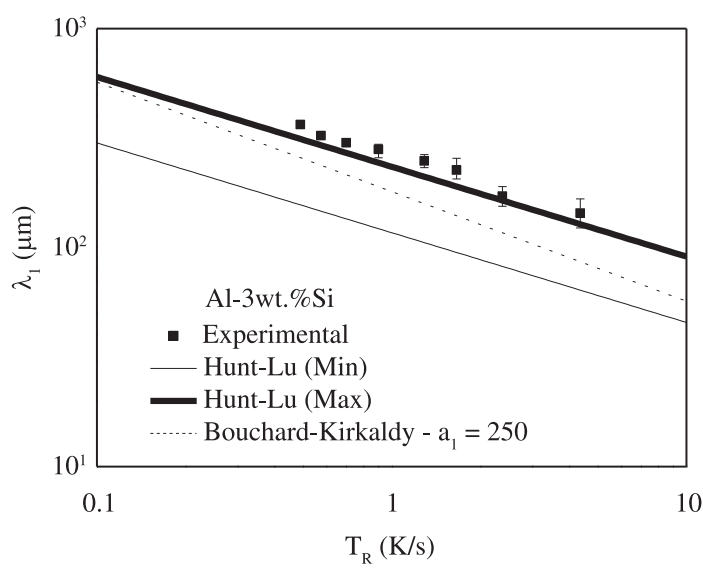

Figure 14. Comparison of experimental and theoretical primary dendrite arm spacings as a function of cooling rate for the Al$3 \mathrm{wt}$ \% Si alloy in unsteady-state horizontal directional solidification.

the occurrence of physical effects in liquid (growth kinetics of the dendrites, dendrite arm spacings, formation of interdendritic liquid, dendrite arm detachment and fragmentation, thermosolutal convection and equiaxed grain density) quite different from those observed during upward and downward vertical solidification

\section{Conclusions}

The following major conclusions can be drawn from this study, where Al-3wt.\%Si alloy has been directionally solidified under unsteady-state heat flow conditions:

- The present theoretical-experimental investigation was capable of predicting satisfactorily the heat transfer coefficient at metal-mold interface during horizontal directional solidification of Al-3wt.\% Si alloy in a stainless steel mold with the thermal contact condition at the heat extracting surface being polished cooled. This coefficient can be expressed as a power function of time, given by $h_{i}=3800(t)^{-0.38} \mathrm{~W} / \mathrm{m}^{2} \mathrm{~K}$;

- For this case, the basic feature of the CET is that the transition is sharp, i.e., the CET occurs along a plane parallel to the chill wall because of the high density of rapidly growing equiaxed grains. The CET has occurred for a tip growth rate, for a tip cooling rate and for a thermal gradient in the melt of about 0.26 $\mathrm{mm} / \mathrm{s}, 0.44 \mathrm{~K} / \mathrm{s}$ and $1.68 \mathrm{~K} / \mathrm{mm}$, respectively;

- The experimental results were compared with theoretical predictions furnished by a numerical model and a good agreement was observed between experimental and simulated solidification thermal variables. Thus, the experimental equations proposed are capable of representing quite approximately the solidification thermal variables $V_{L}, T_{R}$ and $G_{L}$ as a function of position from the metal-mold interface;

- Primary dendrite arm spacings were observed to decrease as the tip growth rate or the tip cooling rate increased. A power law function characterizes the experimental variation of primary spacings with tip growth rate with an index of -1.1 as well as a -0.55 power law characterizes the experimental variation of primary spacings with cooling rate; 
- The theoretical primary spacing models by HuntLu and Bouchard-Kirkaldy did not generate the experimental observations concerning the unsteadystate solidification of the Al-Si alloy examined. The dendritic primary spacing experimental scatter is not included inside the range of minimum and maximum $\lambda_{1}$ values predicted by Hunt-Lu's model. BouchardKirkaldy model's predictions underestimate the experimental points.

\section{References}

1. Flood SC and Hunt JD. A model of a casting. Applied Science Research. 1987; 44:27-42. http://dx.doi.org/10.1007/ BF00412004

2. Canté MV, Cruz KS, Spinelli JE, Cheung N and Garcia A. Experimental analysis of the columnar-to-equiaxed transition in directionally solidified Al-Ni and Al-Sn alloys. Materials Letters. 2007; 61:2135-2138. http://dx.doi.org/10.1016/j. matlet.2006.08.032

3. Ziv I and Weinberg F. The columnar-to-equiaxed transition in Al 3pct Cu. Metallurgical Transactions B. 1989; 20B:731-734.

4. 4. Peres MD, Siqueira CA and Garcia A. Macrostructural and microstructural development in Al-Si alloys directionally solidified under unsteady-state conditions. Journal of Alloys and Compounds. 2004; 381:168-181. http://dx.doi. org/10.1016/j.jallcom.2004.03.107

5. Silva JN, Moutinho DJ, Moreira AL, Ferreira IL and Rocha OL. The columnar to equiaxed transition during the horizontal directional solidification of $\mathrm{Sn}-\mathrm{Pb}$ alloys. Journal of Alloys and Compounds. 2009; 478:358-366. http://dx.doi.org/10.1016/j. jallcom.2008.11.026

6. Hunt JD. Steady state columnar and equiaxed growth of dendrites and eutetic. Materials Science and Engineering. 1984; 65:7583. http://dx.doi.org/10.1016/0025-5416(84)90201-5

7. Flood SC and Hunt JD. Columnar and equiaxed growth i. a model of a columnar front with a temperature dependent velocity. Journal of Crystal Growth. 1987; 82:543-551. http:// dx.doi.org/10.1016/0022-0248(87)90346-0

8. Flood SC and Hunt JD. Columnar and equiaxed growth ii. equiaxed growth ahead of a columnar front. Journal of Crystal Growth. 1987; 82:552-560. http://dx.doi.org/10.1016/00220248(87)90347-2

9. Wang CY and Beckermann C. Prediction of columnar to equiaxed transition during diffusion-controlled dendritic alloy solidification. Metallurgical and Materials Transactions A. 1994; 25A:1081-1093.

10. Dong HB and Lee PD. Simulation of the columnar-to-equiaxed transition in directionally solidified Al-Cu alloys. Acta Materialia. 2005; 53:659-668. http://dx.doi.org/10.1016/j. actamat.2004.10.019

11. Badillo A and Beckermann C. Phase-field simulation of the columnar-to-equiaxed transition in alloy solidification. Acta Materialia. 2006; 54:2015-2026. http://dx.doi.org/10.1016/j. actamat.2005.12.025

12. Okamoto $\mathrm{T}$ and Kishitake $\mathrm{K}$. Dendritic structure in unidirectionally solidified aluminum, tin, and zinc base binary alloys. Journal of Crystal Growth. 1975; 29:137-146. http:// dx.doi.org/10.1016/0022-0248(75)90217-1

13. Kurz W and Fisher JD. Dendrite growth at the limit of stability: tip radius and spacing. Acta Metallurgica. 1981; 29:11-20. http://dx.doi.org/10.1016/0001-6160(81)90082-1

\section{Acknowledgements}

The authors acknowledge the financial support provided by IFPA (Federal Institute of Education, Science and Technology of Pará), UFPA (Federal University of Pará), Brazil, and CNPq (The Brazilian Research Council). C.M. Macedo de Macedo, from the Federal University of Pará, is also acknowledged for her careful reading of the manuscript.

14. Hunt JD and Lu SZ. Numerical modeling of cellular/dendritic array growth: spacing and structure predictions. Metallurgical Materials Transactions A. 1966; 27A:611-23.

15. McCartney DG and Hunt JD. Measurements of cell and primary dendrite arm spacings in directionally solidified aluminium alloys. Acta Metallurgica. 1981; 29:1851-1863. http://dx.doi. org/10.1016/0001-6160(81)90111-5

16. Bouchard D and Kirkaldy JS. Scaling of intragranular dendritic microstructure in ingot solidification. Metallurgical Materials Transactions B. 1996; 27B:101-113.

17. Bouchard D and Kirkaldy JS. Prediction of dendrite arm spacings in unsteady and steady-state heat flow of unidirectionally solidified binary alloys. Metallurgical and Materials Transactions. 1997; 28B:651-663.

18. Gündüz $M$ and Çardili E. Directional solidification of aluminium-copper alloys. Materials Science and Engineering: A. 2002; 327:167-185. http://dx.doi.org/10.1016/S09215093(01)01649-5

19. Rocha OL, Siqueira CA and Garcia A. Cellular/dendritic transition during unsteady-state unidirectional solidification of Sn-Pb alloys. Materials Science and Engineering: A. 2003; 347:59-69. http://dx.doi.org/10.1016/S09215093(02)00581-6

20. Rocha OL, Siqueira CA and Garcia A. Heat flow parameters affecting dendrite spacings during unsteady-state solidification of $\mathrm{Sn}-\mathrm{Pb}$ and $\mathrm{Al}-\mathrm{Cu}$ alloys. Metallurgical and Materials Transactions A. 2003; 34:995-1006. http://dx.doi.org/10.1007/ s11661-003-0229-3

21. Ordorica MAS and Rappaz M. Twinned dendrite growth in binary aluminum alloys. Acta Materialia. 2008; 56:5708-5718. http://dx.doi.org/10.1016/j.actamat.2008.07.046

22. Rosa DM, Spinelli JE, Ferreira IL and Garcia A. Cellular/ dendritic transition and microstructure evolution during transient directional solidification of $\mathrm{Pb}$-Sb alloys. Metallurgical and Materials Transactions. 2008; 39:2161-2174. http://dx.doi. org/10.1007/s11661-008-9542-1

23. Cruz KS, Meza ES, Fernandes FAP, Quaresma JMV, Casteletti LC and Garcia A. Dendritic arm spacing affecting mechanical properties and wear behavior of Al-Sn and Al-Si alloys directionally solidified under unsteady-state conditions. Metallurgical and Materials Transactions. 2010; 41:972-984. http://dx.doi.org/10.1007/s11661-009-0161-2

24. Wu M, Fjeld A and Ludwig A. Modelling mixed columnarequiaxed solidification with melt convection and grain sedimentation-Part I: Model description. Computational Materials Science. 2010; 50:32-42. http://dx.doi.org/10.1016/j. commatsci.2010.07.005

25. Wu M, Ludwig A and Fjeld A. Modelling mixed columnar-equiaxed solidification with melt convection and grain sedimentation-Part II: Illustrative modelling results and parameter studies. Computational Materials Science. 2010; 50:43-58. http://dx.doi.org/10.1016/j. commatsci.2010.07.006 
26. Gandin CA and Rappaz M. A 3D cellular automation algorithm for the prediction of dendritic grain growth. Acta Materialia. 1997; 45:2187-2195. http://dx.doi.org/10.1016/ S1359-6454(96)00303-5

27. Kremeyer K. Cellular automata investigations of binary solidification. Journal of Computational Physics. 1998; 142:243-262. http://dx.doi.org/10.1006/ jcph.1998.5926

28. Wang W, Lee PD and McLean M. A model of solidification microstructures in nickel-based superalloys: predicting primary dendrite spacing selection. Acta Materialia. 2003; 51:29712987. http://dx.doi.org/10.1016/S1359-6454(03)00110-1

29. Zhao $P$ and Heinrich JC. Numerical approximation of a thermally driven interface using finite elements. International Journal for Numerical Methods in Engineering. 2003; 56:15331547. http://dx.doi.org/10.1002/nme.621

30. Al-Rawahi $\mathrm{N}$ and Tryggvason G. Numerical simulation of dendritic solidification with convection: three-dimension flow. Journal of Computational Physics. 2004; 194:677-696. http:// dx.doi.org/10.1016/j.jcp.2003.09.020

31. Zhu MF and Stefanescu DM. Virtual front tracking model for the quantitative modeling of dendritic growth in solidification of alloys. Acta Materialia. 2007; 55:1741-1755. http://dx.doi. org/10.1016/j.actamat.2006.10.037

32. Provatas N, Goldenfeld N and Dantzig J. Efficient computation of dendritic microstructures using adaptive mesh refinement. Physical Review Letters. 1998; 80:3308-3311. http://dx.doi. org/10.1103/PhysRevLett.80.3308

33. Plapp M and Karma A. Multiscale random-walk algorithm for simulating interfacial pattern formation. Physical Review Letters. 2000; 84:17401-17443. http://dx.doi.org/10.1103/ PhysRevLett.84.1740

34. Warren JA and George WL. A parallel 3D dendritic growth simulator using the phase-field method. Journal of Computational Physics. 2002; 177:64-283.

35. Gibou F, Fedkiw R, Caflisch R and Osher S. A level set approach for the numerical simulation of dendritic growth. Journal of Scientific Computing. 2003; 19:183-199. http:// dx.doi.org/10.1023/A:1025399807998

36. Tan L and Zabaras N. A level set simulation of dendritic solidification of multi-component alloys. Journal of
Computational Physics. 2007; 221:9-40. http://dx.doi. org/10.1016/j.jcp.2006.06.003

37. Djurdjevič MB and Grzinčič MA. The effect of major alloying elements on the size of the secondary dendrite arm spacing in the as-cast Al-Si-Cu alloys. Archives of Foundry Engineering. 2012; 12:19-24. http://dx.doi.org/10.2478/ v10266-012-0004-2

38. Rooy EL. Casting. In: Metals Handbook. 9th ed. Materials Park: ASM International; 1988. p. 743-770.

39. Rooy EL. Properties and Selection: Nonferrous Alloys and Special-Purpose Materials. In: Metals Handbook. 9th ed. Materials Park: ASM International; 1990. p. 490-539.

40. Spinelli JE, Ferreira IL and Garcia A. Evaluation of heat transfer coefficients during upward and downward transient directional solidification of Al-Si alloys. Structural Multidisciplinary Optimization. 2006; 31:241-248. http://dx.doi.org/10.1007/ s00158-005-0562-9

41. Ferreira IL, Spinelli JE, Nestler B and Garcia A. Influences of solute content, melt superheat and growth direction on the transient metal/mold interfacial heat transfer coefficient during solidification of $\mathrm{Sn}-\mathrm{Pb}$ alloys. Materials Chemistry and Physics. 2008; 111:444-454. http://dx.doi.org/10.1016/j. matchemphys.2008.04.044

42. Spinelli JE, Ferreira IL and Garcia A. Influence of melt convection on the columnar to equiaxed transition and microstructure of downward unsteady-state directionally solidified $\mathrm{Sn}-\mathrm{Pb}$ alloys. Journal of Alloys and Compounds. 2004; 384:217-226. http:// dx.doi.org/10.1016/j.jallcom.2004.04.098

43. Cheung N, Ferreira IL, Pariona MM, Quaresma JMV and Garcia A. Melt characteristics and solidification growth direction with respect to gravity affecting the interfacial heat transfer coefficient of chill castings. Materials \& Design. 2009; 30:3592-3601. http://dx.doi.org/10.1016/j. matdes.2009.02.025

44. Cheung N, Santos NS, Quaresma JMV, Dulikravich GS and Garcia A. Interfacial heat transfer coefficients and solidification of an aluminum alloy in a rotary continuous caster. International Journal of Heat and Mass Transfer. 2009; 52:451-459. http:// dx.doi.org/10.1016/j.ijheatmasstransfer.2008.07.003 